\title{
Coulisses
}

Revue de théâtre

13 | Hiver 1996

Varia

Diffusion

\section{Diffusion : La Grande Parade au Cabaret de l'Ange bleu}

Lucile Garbagnati

\section{OpenEdition}

\section{Journals}

Édition électronique

URL : http://journals.openedition.org/coulisses/4257

DOI : $10.4000 /$ coulisses.4257

ISSN : 2546-9460

\section{Éditeur}

Presses universitaires de Franche-Comté

Édition imprimée

Date de publication : 1 janvier 1996

Pagination : 65

ISSN : 1150-594X

Référence électronique

Lucile Garbagnati, «Diffusion : La Grande Parade au Cabaret de l'Ange bleu », Coulisses [En ligne], 13|

Hiver 1996, mis en ligne le 15 mars 2019, consulté le 08 octobre 2020. URL : http://

journals.openedition.org/coulisses/4257 ; DOI : https://doi.org/10.4000/coulisses.4257

Ce document a été généré automatiquement le 8 octobre 2020.

Coulisses 


\title{
Diffusion
}

\section{Diffusion : La Grande Parade au Cabaret de l'Ange bleu}

\author{
Lucile Garbagnati
}

17 novembre 1995, Opéra théâtre.

Théâtre musical. Livret d'après Grand'peur et misère du III ${ }^{\text {ème }}$ Reich de Bertolt Brecht. Metteur en scène Charlie Brozzoni. Compositieur, Etienne Perruchon.

Propos recueillis par Lucile Garbagnati

1 La Compagnie Brozzoni pendant les quelques jours où elle est restée dans la région a honoré sa parole "d'être taillable et corvéable à merci ». Elle a répondu à toutes les invitations d'animation qui lui étaient faites et c'est ainsi que son directeur et metteur en scène Charlie Brozzoni et le chef d'orchestre ont exposé leur conception du théâtre aux étudiants du module de DEUG : Le théâtre au XX ${ }^{\text {ème }}$ siècle.

\section{Une compagnie qui croit dans son action}

2 Dans le contexte actuel, état de guerre, de siège social permanent, où la parole extrémiste trouve un auditoire croissant, la culture doit assumer sa véritable fonction qui est l'harmonie de la société, comme parole d'une communauté. Le théâtre c'est véritablement chercher l'homme. Comme le dit Tennessee Williams, comment arriver à construire le paradis sur terre avec ses défauts même? Il s'agit de réinventer des utopies. Le théâtre n'est pas un luxe, mais une nécessité.

\section{Grand'peur et misère du IIIème Reich}

3 C'est une pièce qui, écrite au quotidien des années 30, anticipe, peut-être, sur les retombées de notre actualité. Elle montre le processus qui enclenche toutes les dictatures et la responsabilité personnelle des individus. 


\section{Le cabaret}

4 Deux idées ont guidé la forme choisie du cabaret :

- l'hommage au " cabaret » comme genre. C'est là que se sont battus tant d'artistes qui ont pris le risque de diffuser leur art au péril de leur sécurité, voire de leur vie ; l'envie que les gens sortent du spectacle en disant : «je suis vivant » et qu'ils y trouvent leur énergie. Redonner une mémoire de l'histoire, c'est engager les spectateurs à la vigilance, sans orientation politique partisane.

\section{La musique}

Dans cette forme, elle tient une grande place. Etienne Perruchon a rencontré Charlie Brozzoni en 1989 et depuis «ils ne se quittent pas ». Tous deux obéissent à la même obligation "j'écris ce que je suis ; et ce que l'on pense, ça s'entend et ça se voit. » La musique est composée en même temps que s'élabore le spectacle. Les musiciens sont des professionnels alors que les acteurs ont pris des cours de chant et de danse mais sont avant tout des acteurs.

\section{La vie de la troupe:}

6 Tout est fait par le groupe, mais le metteur en scène est le seul responsable. Le travail d'improvisation est là pour mettre au jour l'imaginaire de l'acteur et ainsi enrichir le spectacle.

\section{Respect du texte ou adaptation ?}

7 Il s'agit d'un montage de tableaux de Grand'peur, six sur vingt-quatre ont été repris. L'essentiel est de faire passer le message. C'est pourquoi, à l'instar des songs de Brecht, V. Arbez, également actrice, a composé des chansons, à la résonance contemporaine. Écoutons celle du rappel :

Devant derrière en face et de tous les côtés Ca cogne et ça crie c'est ça l'humanité.

On l'savait depuis qu'on est né

D'l'auberge on n'est pas barré, Mais faut espérer.

Refrain final :

On a bien l'droit d'y croire C'est pas que d'la mélodie Elle peut être belle l'histoire Si c'est celle de la vie. 